\title{
Low profile, high impact: the role of the sociologist in quality in health care
}

\author{
Rosemary Chesson
}

It was claimed over 50 years ago that medicine cannot do without sociology, 'but what impact have sociologists had on quality of health care? Most clinicians and managers would not be able to identify sociology's contribution even though it forms part of the educational preparation of healthcare professionals, including medical practitioners. Why does sociology seem invisible when it is so relevant to health care in a rapidly changing society? The declining social importance of hospital clinicians in the 1990s, for example, shows how important all the social structure of medicine is for all disciplines. In this article I have evaluated the unique role of sociology in determining quality and main methods of investigating aspects of health and illness. Reasons for sociology's low profile are discussed and future opportunities delineated.

\section{Sociology: its definition and concerns, with reference to health and illness}

Sociology investigates how society is organised and examines the processes by which it is maintained or changed. Sociology is about how society works at the levels of institutions and organisations and what beliefs and attitudes (ideologies) support or challenge this. ${ }^{2}$ The subject is based on critical analysis whereby nothing is taken for granted, ${ }^{3}$ not even the existence of sociology. The distinguishing features of sociology are (a) the systematic and objective study of human society, and (b) the sociological imagination, ${ }^{+}$with which it can be seen that "personal troubles of milieu" are connected with "public issues of social structure". ${ }^{5}$ A keystone for sociology is exploring the links between behaviour and social structure (social institutions such as government). Nowhere is this better illustrated than in the area of health and illness.

\section{Sociological autonomy}

During the $1950 \mathrm{~s}$, both in Britain and the United States, medical sociology established itself as an academic discipline based on the methods and theories of mainstream sociology applied to medicine. Initially sociologists worked largely in a subservient role on problems identified by doctors, ${ }^{\circ}$ but this changed rapidly. The medical profession itself became the subject of investigation and American sociologists in particular examined critically the power of doctors, ${ }^{7}$ and pointed to the "medicalisation" of social life. ${ }^{8}$ In Britain, sociologists promoted a social model of illness and doctors, the proponents of the medical model, were regarded as failing to solve the social causes of disease. Subjective experience of illness was highlighted as crucial to understanding behaviour during illness (box 1)." In less than two decades sociologists developed their own research agenda published in new journals, which helped to establish their autonomy. In Britain the Medical Research Council established a Sociology Unit. Incorporation within medicine, as a paramedical profession, never occurred.

This autonomy has had important implications for health care. Sociologists, situated outside of the system and educated apart, brought a new vision. Cherished assumptions were challenged and different questions were asked from those of professionals trained within the confines of a medical curriculum. From the subject's earliest days medical sociologists opened up new and fruitful areas for investigation and discussion. For example, research in the early $1950 \mathrm{~s}^{11}$ showed that people seemed to experience symptoms much more often than they consultated their doctors. Early sociological surveys helped to

INITIAL STAGE: sociology in medicine

Sociology acts as tool for medicine, clinicians set agenda.

Key issues: social role of medicine; social factors in illness prevalence; consultation rates especially in general practice.

\section{TRANSITIONAL STAGI: sociology of} medicine

Sociology develops own focus of interest. Medicine itself subject to sociological scrutiny. Emphasis on theory and application of concepts.

Key issues: Medical power and control; patient experience of illness and medical organisation

CONSOLIDATION STAGE: sociology of health and illness

Increasing areas of health care examined by sociologists; medical boundaries challenged, feminist perspectives incorporated Key issues: definitions of health and illness and patients' perspectives.

COLLABORATIVE STAGE? Sociology of health Sociologists seek partnerships with clinicians in investigation of problems. Doctors incorporate sociological perspectives especially for rehabilitation, care in the community, and health promotion.

Key issues: health; lifestyle; health beliefs; social support; alternative treatments, outcomes.

Box 1 Main trends in sociological perspectives on health care 
establish the importance of patients' views of treatment and care.

In contrast with medical or managerial investigations, sociological studies have shown the unintended consequences of health care. Certain practices within mental institutions helped to create a "total institution", counterproductive to treatment. ${ }^{11}$ This highly influential concept illustrates two major elements of the sociologist's role in quality in health care - namely, the development of theories and concepts resulting in a better understanding of health, illness, and health care, and methods for describing and evaluating health care.

Theoretical and conceptual development New ways of thinking about illness and health care resulted from publications in the 1950s with health and illness as key factors in the maintenance of social stability (equilibrium). ${ }^{12}$ These key factors thus needed to be controlled. ${ }^{13}$ Illness and behaviour during illness were seen to follow prescribed forms (as formulated in the sick role), with the patient, physician, and any other person involved having the shared goal of recovery. Illness was seen at best as disfunctional and at worst deviant. More radically, medical ideology was fundamentally challenged: "the medical establishment has become a threat to health. The disabling impact of professional control over medicine has reached the proportions of an epidemic". ${ }^{14}$ This concept of iatrogensis has now become embedded in sociology, alongside such concepts as stigma, applied to illness and defined as "the situation of the individual who is disqualified from full social acceptance". ${ }^{15}$ Over the years this concept has been widely used to describe feelings associated with disease and disability, both by researchers and patients. The stigmatising effects of both physical $^{16}$ and mental illness ${ }^{17}$ have been explored - for example, in research on AIDS ${ }^{18}$ and epilepsy. ${ }^{19}$ Stigma was found to be very strong indeed in people with epilepsy; only 5\% of patients included in one study told employers of their disorder and only 33\% informed their fiancees. Clearly healthcare professionals have to acknowledge and consider such issues.

The book The meaning of disability ${ }^{20}$ has had a major influence on disability research and subsequent work has confirmed that services need to be well coordinated ${ }^{21}$ and that continuity in care is crucial. ${ }^{22}$ With care in the community, a common fear is that the quality of care will be compromised. ${ }^{23}$ Sociological research which showed that long stay care was dehumanising for patients through such practices as "identity stripping" 24 and "batching" 25 has tended to be forgotten. High quality care, however, may be provided by family members in the community, who offer comfort, companionship, and respect dignity. ${ }^{26}$ Although early studies highlighted the strain on carers $^{27}$ and the extent to which women were relied on, ${ }^{28}$ more recent research has shown that caring can provide satisfaction ${ }^{29}$ and give purpose to life. ${ }^{26}$ Sociological theories and studies on the family and community - important foundations for the discipline - are vital in providing a framework for understanding and planning community care. Ultimately the feasibility of care in the community may depend on the quality of care provided by informal carers, and health professionals' ability to assess and harness that care. The Black report ${ }^{30}$ which stressed social factors in health recommended long ago that statutory services should be seen to supplement rather than substitute family care. ${ }^{31}$ If health is to be promoted health services may need in some situations to perform functions, such as support, previously provided by family members. ${ }^{32}{ }^{33}$ In the future quality of health care is likely to become inextricably linked to research on interpersonal relations, the family, and neighbourhood networks.

Sociological theories and studies on stratification encompassing class, age, sex, and race have stimulated and contributed to research on social inequality in health and health care. Conceptual underpinning has been provided for understanding why women have higher rates of mental illness. ${ }^{34}$ how different social classes respond to symptoms ${ }^{10}$ and participate in medical consultations, ${ }^{35}$ and why there is differential access to good medical care. ${ }^{36}$ Sociological surveys of deprivation and poverty contributed to the Black report, ${ }^{30}$ the formulation of the farman index, ${ }^{37}$ and the recommendations of the Acheson report on public health. ${ }^{38}$ Jarman's system of compensatory payments, related to levels of social deprivation in the community, was an important attempt to improve quality of care in the community through encouraging the purchase of additional staff by general practitioners.

\section{Assessing quality of health care}

Research into health care has relied largely on quantitative methods, ${ }^{39}$ and sociologists helped to establish the survey in health services research through their established reputation in surveying and questionnaire design. ${ }^{40}$ Specific contributions have also been important in the development and evaluation of health measurement. ${ }^{41}$ New approaches have been advocated, however, as awareness has grown of the limitations of quantitative methods. Although randomised clinical trials have been regarded as the gold standard for effectiveness research, there is increasing recognition of their fallibility. Problems of blinding and exclusions have been reported recently by medical practitioners, ${ }^{42}$ extending criticisms put forward earlier by sociologists. ${ }^{43}$

Dissatisfaction with validated measures such as the short form 36 (SF-36), ${ }^{44}$ and increasing emphasis on patient defined outcome ${ }^{45}$ has created a need to develop new tools. Yet questionnaires are not easy to design. ${ }^{46}$ Objectives will not then be met, ${ }^{47}$ as "poor questionnaires act as a form of censorship". ${ }^{48}$ High levels of research competence are required, as qualitative studies have shown.

Qualitative methods have been described as having an "enormous potential to illuminate the impact of care on patients". ${ }^{49}$ Doctors today may find qualitative methods more 
acceptable given that they have been exhorted to discover patients' existing knowledge, "rather than treat them as empty vessels into which "appropriate" knowledge can be poured". ${ }^{50}$ Qualitative methods in medical and health publications are now being promoted 30 years after they were advocated in sociological journals. Two of the studies highlighted in recent articles, ${ }^{49} 51$ on patients presenting headaches to a neurological clinic, ${ }^{47}$ and on surgical decision making processes, ${ }^{52}$ were carried out over 10 and 20 years ago respectively. Although different rates of tonsillectomy in adjacent small areas in Scotland were found ${ }^{52}$ only recently have qualitative methods been suggested as a means to examine variation in clinical practice. ${ }^{53}$

Qualitative approaches could be used to discover why research findings are not applied to clinical practice ${ }^{54}$ and to better understand medical practice so that clinical behaviour might be changed. ${ }^{55}$ Indeed, a qualitative study based on four district hospitals has shown recently that although some obstacles to audit could be overcome by simple practical measures others would require a change in doctors' knowledge, beliefs, and attitudes. ${ }^{56}$

\section{Sociology in professional education}

Sociology is included in the education and training of a wide range of healthcare professionals. Sociology is incorporated in both the medical undergraduate and postgraduate curriculums - for example, it forms part of the membership of the Royal Colleges of Psychiatry and General Practice, and the Faculty of Public Health Medicine. Medical educationalists have long seen the need for practitioners to understand the relation between health care and the structure of society. The role of sociology in helping to understand behaviour of patients has become increasingly important: "Demographic change and medical advances mean that the main challenge now confronting doctors is managing chronic conditions in such a way as to maximise the social functioning of patients. In many instances long term drug treatment will have to be combined with dietary or some other form of intervention, with obvious implications for enlisting and maintaining patients' cooperation. If this is to be achieved doctors must understand better the lives in which they are intervening." 50

A specific recommendation of Tomorrow's doctors is that courses on human development and aspects of psychology and sociology relevant to medicine should feature on all curriculums. ${ }^{57}$

\section{Impact of sociologists}

Despite the wide ranging nature and long lasting effects of the sociologist's contribution to health care as shown by work in psychiatry (box 2), ${ }^{58}$ a common perception is that it has not had a major impact on quality of care.

There are several reasons why this may be so.
LOW PROFILE OF SOCIOLOGISTS

Sociology is a small profession, current membership of the British Sociological Association is about 3500 . Few sociologists are employed in the National Health Service (NHS). Few work in NHS trusts (more are employed in departments of public health) and they rarely act as facilitators or serve as members of audit committees. Their voice has not been heard in quality debates. Sociologists usually publish in sociology journals (Social Science in Medicine; Sociology of Health and Illness) rather than in clinically oriented publications. Even when they write for more general journals, their language and emphasis on theory discourages readers. Often there is a long time lag between initial publication and health professionals' awareness of sociological research.

\section{NATURE OF SOCIOLOGY}

Clinical work is case bound, concrete, and always is situationally specific. ${ }^{59}$ By contrast with the practical and pragmatic nature of medicine, sociology is an analytical science and can, at best, prescribe. ${ }^{60}$ Medical students may find sociology frustrating because it accentuates pre-existing worries about medicine, without offering practical solutions. ${ }^{61}$

\section{LACK OF JOINT WORKING BETWEEN CLINICIANS} AND SOCIOLOGISTS

Close collaboration seldom occurs between sociologists, healthcare professionals, and managers.

Sociologists fear loss of independence, and prefer generally to work in university departments of sociology - which are regarded as having lower status and often lack

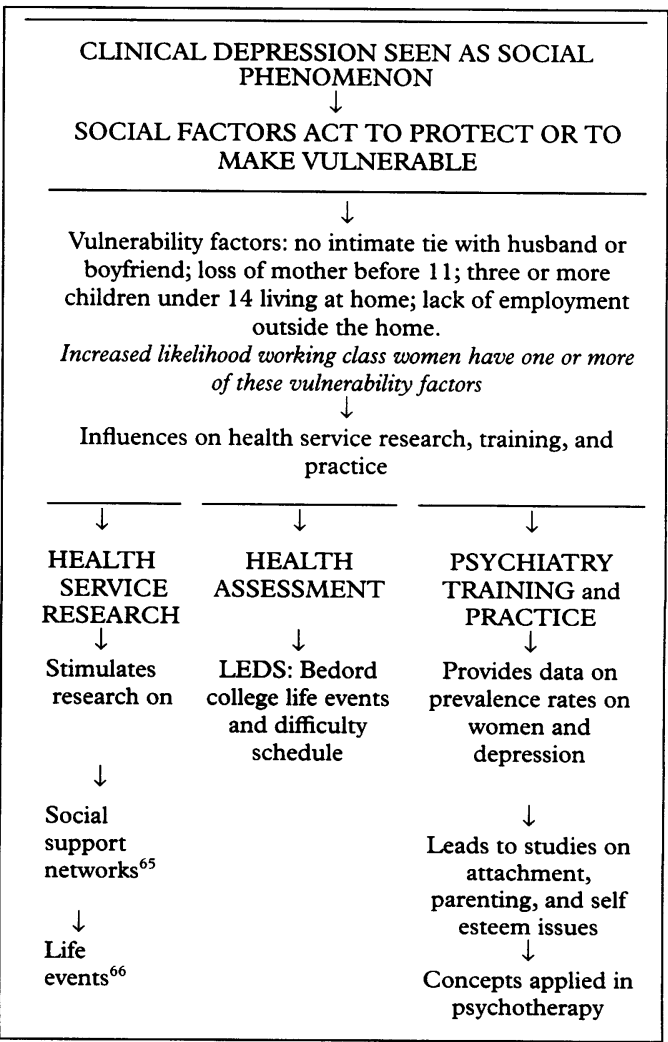

Box 2 Case illustration: research on social origins of depression 


\begin{tabular}{|c|c|}
\hline $\begin{array}{l}\text { Surgeon's problem } \\
\text { In certain routine types of } \\
\text { surgical operations } \\
\text { (particularly ulcer surgery) } \\
\text { the long term outcome for } \\
\text { some patients did not seem } \\
\text { to bear any direct or obvious } \\
\text { relation to the technical } \\
\text { success of the operation. }\end{array}$ & $\begin{array}{l}\text { Sociologist's problem } \\
\text { Coping with surgery for } \\
\text { ulcerative colitis and good } \\
\text { long term adjustment to } \\
\text { ileostomy, had no clear } \\
\text { relation either to presurgical } \\
\text { experiences with the } \\
\text { disease, or to postoperative } \\
\text { medical or surgical } \\
\text { complications, or their } \\
\text { absence. }\end{array}$ \\
\hline
\end{tabular}

Box 3 Interdisciplinary research: identification of common problems (modified from Kelly et $a^{t^{4}}$ )

tenure - rather than in clinical settings. Doctors have stereotyped sociologists in the past as scruffy and left wing. Sociological work is often critical of medicine - for example, that on the "medicalisation" of maternity care is a case in point. $^{62}$

LACK OF INTEREST IN HEALTH SERVICE RESEARCH In former years most healthcare professionals have not needed to become involved in research, particularly that relating to delivering health care. Despite social and behavioural obstacles to outcome measurement in clinical practice being identified in $1972,{ }^{63}$ clinicians showed little interest in determining precisely what these were, or how they might be overcome. When sociological research on clinical effectiveness was encountered by medical practitioners it was often seen as lacking in scientific rigour.

\section{The future}

Recognition of the value of qualitative research and emphasis on patients' perspectives in care indicate that health care may have a greater need of sociologists than ever before. The necessity to understand better the processes by which research evidence affects clinical practice, and how high quality health care can be sustained in the community, means that considerable opportunities exist for sociologists to help to improve quality in health care. This may be achieved best by collaborative work for example, a joint research project between a surgeon and a sociologist. ${ }^{64}$ Although a similar problem was identified from different starting points (box 3) both the surgeon and the sociologist were unaware of this until, through luck, a colleague brought the two together. Too often sociologists and healthcare professionals are not aware that they share common concerns; brokers may be required.

Increased opportunities for contact are needed, and joint initiatives by professional associations may be useful. Multidisciplinary journals too have an important part to play; Quality in Health Care has sociologists and healthcare professionals as contributors and readers. At local levels closer links could be forged between sociologists in universities and healthcare professionals and staff in quality departments in trusts and health authorities or boards. Through such strategies a closer involvement of sociologists and the sociological perspective in assessment of quality in health care and health services research may be achieved to the benefit of both patients and clinicians.
I thank Drs Ann Bisset and Cleo Hart for their comments on an earlier version of this paper, as well as Dr Richard Thomson for his valuable editorial advice.

1 Jeffries M. Cited by: Patrick DL, Scambler G, eds. Sociology as applied to medicine. London: Billiere Tindall, 1982.

2 Thorogood $\mathrm{N}$. What is the relevance of sociology for health promotion? In: R Bunton, $G$ Macdonald, eds. Health promotion. Disciplines and diversity. London: Routledge and Ketion. Disciplines

3 Berger P. Invitation to sociology. Harmondsworth: Penguin, 1963.

4 Giddens A. Sociology. 2nd ed. London: Polity, 1993.

5 Mills CW. The sociological imagination. Oxford: Oxford University Press, 1959.

6 Strong PM. Sociological imperialism and the profession of medicine. Soc Sci Med 1979;13A:199-215.

7 Zola IK. Medicine as an institution of social control. Sociology Review 1972;20:487-503.

8 Illich F. Medical nemesis. London; Calder and Boyars, 1978.

9 Davis A, Horobin G. Medical encounters. London: Croom Helm, 1972.

10 Koos EL. The health of Regionsville. What the people thought and did about it. New York: Hafner, 1954.

11 Goffman E. Asylums. Harmondsworth: Penguin, 1963.

12 Parsons T. The social system. London: Tavistock, 1951.

13 Parsons T. Illness and the role of the physician. $A m \mathcal{F}$ Orthopsychiatry 1951;21:452-60.

14 Illich I. Limits to medicine. London: Calder and Boyars, 1974

15 Goffman E. Stigma. Notes on the management of spoiled identity. Englewood Cliffs, NJ: Prentice Hall, 1963.

16 Anderson R, Bury $M$, eds. Living with chronic illness. London: Unwin Hyman, 1988.

17 Turner BS. Medical power and social knowledge. London: Sage, 1987.

18 Holland J, Ramazanoglu C, Scott S. AIDS: from panic stations to power relations, sociological perspectives and problems. Sociology 1990;25:499-518.

19 Scambler G, Hopkins A. Generating a model of epileptic stigma: the role of qualitative analysis. Soc Sci Med 1990;35:118794.

20 Blaxter M. The meaning of disability. London: Heinemann, 1976.

21 Beardshaw V. Last on the list: community services for people with physical disabilities. London: Kings Fund Institute, 1988.

22 Anderson R. The aftermath of stroke. Cambridge: Cambridge University Press, 1992

23 Bowling A, Farquhar M, Grundy E. Who are the consistently high users of health and social services? A follow-up study two and a half years later of people aged 85+ at baseline. Health and Social Care 1993;1:277-87.

24 Jones $\mathrm{K}$, Fowles AJ. Ideas on institutions: analysing the literature on long term care and custody. London: Routledge and Kegan Paul, 1984.

25 Jones K. $A$ history of the mental health services. London: Routledge and Kegan Paul, 1972.

26 Twigg J, Atkin K. Carers perceived. Buckingham: Open University Press, 1994.

27 Anderson R. The unremitting burden on carers. BMF 1987; 294:6564.

28 Finch J, Groves D, eds. A labour of love: women, work, and caring. London: Routledge and Kegan Paul, 1983.

29 Qureshi H, Walker A. The caring relationship. Elderly people and their families. London: Macmillan, 1989.

30 Townsend P, Davidson N. Inequalities in health: the Black report. Harmondsworth: Penguin, 1982.

31 Townsend P. The family life of old people. London: Routledge, 1957.

32 Gottlieb B. Social networks and social support: an overview of research, practice and policy implications. Health Educ $Q$ 1985;12:5-22.

33 Morgan M, Patrick O.L, Charlton J.R. Social networks and psychosocial support among disabled people. Soc Sci Med 984:19:489-97.

34 Busfield J. Mental illness as a social product or social construct: a contradiction in feminine arguments. Sociology of Health and Illness 1985;10:521-42.

35 Cartwright A, O'Brien M. Social class variations in health care and in the nature of general practitioner consultations. In: M Stacey, ed. The Sociology of the NHS Keele: tions. In: M Stacey, ed. The Sociology of the NHS . Keele: Monograph 22.)

36 Tudor-Hart J. The inverse care law. Lancet 1971;i:1405-12.

37 Jarman B. Underprivileged areas: validation and distribution of scores. $B M F$ 1984;289:1587-92.

38 Acheson, ED. Public health in England: the Report of the Committee of Inquiry into the Future Development of the Public Health Function. London: HMSO, 1988. (Command 289.)

39 Mays N, Pope C. Qualitative research in health care. London: British Medical Association, 1996.

40 Cartwright A. Health surveys. London: King Edward's Hospital Fund, 1983

41 Bowling A. Measuring health: a review of quality of life measurement scales. Milton Keynes: Open University Press, 1991.

42 Schultz KF, Grimes DA, Altman OG, Hayes RJ. Blinding and exclusions after allocation in randomised controlled trials: survey of published parallel group trials in obstetrics and gynaecology. BMF 1996;312:742-4. 
43 Oakley A. Who's afraid of the randomised controlled trial ? Some dilemmas of the scientific method and 'good' research practice. In: Roberts $\mathrm{H}$, ed. Women's health counts London: Routledge, 1990.

44 Hill S, Harries U, Popay J. Is the short form 36 (SF-36) suitable for routine health outcome assessment in health care for older people? Evidence from preliminary work in community based health services in England. 7 Epidemiol Community Health 1996;50:94-8.

45 Davies A.R. Patient defines outcomes. Quality in Health Care 1994;3:56-9.

46 Chesson $\mathrm{R}$. How to design a questionnaire - a 10 stage strategy. Physiotherapy 1994;9:711-3

47 Fitzpatrick R, Hopkins A. Problems in the conceptual framework of patient satisfaction research: an empirical framework of patient satisfaction research: an empirical exploration. Sociology of Health and Illness 1983;5:297

48 Whitfield $M$, Baker R. Measuring patient satisfaction for audit in general practice. Ouality in Health Care 1992; 3:151

49 Fitzpatrick R, Boulton M. Qualitative methods for assessing health care. Ouality in Health Care 1994;3:107-13.

50 Petchey R, Murphey E. Patient compliance. BMf 1992; 305:1434.

51 Pope C, Mays N. Reaching the parts other methods cannot reach: an introduction to qualitative methods in health and 1995;311:42-5.

52 Bloor $M$. Bishop Berkeley and the adenotonsillectomy enigma: an exploration of variation in the social construction of medical disposals. Sociology 1978;10:43-82.

53 Bury $M$. Health care and chronic illness: a sociological view. Health Care Analysis 1994;24:240-2.
54 Jones R. Why do qualitative research? BMF 1995;311:6996. 55 Hunter D. Are we being effective? Health Sercice fournal $1994 ; 23$

56 Black N, Thompson E. Obstacles to medical audit: British doctors speak. Soc Sci Med 1993;36:849-56.

57 General Medical Council. Tomorrow's doctors: recommendations on undergraduate medical education. London: Kiek and Read, 1993.

58 Brown GW, Harris T. Social origins of depression. London: Tavistock, 1978.

59 Feinstein A.R. Clinical judgement. Baltimore: Williams and Wilkins, 1967 .

60 Gerhardt U. Ideas about illness. New York: New York University Press, 1989.

61 Acton T, Chambers D. Where was sociology in the struggle to re-establish public health ? In: Abbott P, Payne G, eds. New directions in the sociology of health. London: Falme Press, 1990

62 Oakley A. Women confined: towards a sociology of childbirth Oxford: Martin Robertson, 1980.

63 Cochrane A. Effectiveness and efficiency random reflections on health sercices. London: Nuffield Provincial Hospitals Trust, 1972

64 Kelly MP, West P, Anderson J. The chief scientist reports on collaboration: reflections on the preparation of an interdisciplinary research proposal. Health Bull (Edinb) 1990 48:36-40

65 Oakley A, Rajan L. Social class and social support: the same or different? Sociology 1991;25:31-59.

66 Patrick DL, Morgan M, Charlton RH. Psychosocial suppor and change in the health status of physically disabled people. Soc Sci Med 1986;22:1347-54. 